\title{
A Retrospective Analysis of the Relationship between Ethnicity, Body Mass Index, and the Diagnosis of Gestational Diabetes in Women Attending an Australian Antenatal Clinic
}

\author{
Rebecca McDonald, ${ }^{1,2}$ Amalia Karahalios, ${ }^{3,4}$ Thao Le, ${ }^{2,5}$ and Joanne Said ${ }^{5,6}$ \\ ${ }^{1}$ Monash Women's, Monash Health, 246 Clayton Road, Clayton, VIC 3168, Australia \\ ${ }^{2}$ Women's and Children's Health, Sunshine Hospital, Western Health, 176 Furlong Road, Saint Albans, VIC 3021, Australia \\ ${ }^{3}$ Office for Research, Western Centre for Health Research \& Education, 176 Furlong Road, Saint Albans, VIC 3021, Australia \\ ${ }^{4}$ Centre for Epidemiology and Biostatistics, Melbourne School of Population and Global Health, University of Melbourne, \\ 207 Bouverie Street, Carlton, VIC 3053, Australia \\ ${ }^{5}$ Department of Obstetrics and Gynaecology, The University of Melbourne, Parkville, VIC 3052, Australia \\ ${ }^{6}$ Maternal Fetal Medicine, Sunshine Hospital, Western Health, 176 Furlong Road, Saint Albans, VIC 3021, Australia
}

Correspondence should be addressed to Joanne Said; jsaid@unimelb.edu.au

Received 30 May 2015; Revised 10 August 2015; Accepted 13 August 2015

Academic Editor: Alberto Barceló

Copyright (C) 2015 Rebecca McDonald et al. This is an open access article distributed under the Creative Commons Attribution License, which permits unrestricted use, distribution, and reproduction in any medium, provided the original work is properly cited.

\begin{abstract}
Purpose. To estimate the prevalence of gestational diabetes mellitus (GDM) in a multiethnic population, assess the association between country of birth (COB) and GDM, and assess whether the association varies by body mass index (BMI). Methods. A retrospective study of 5260 pregnant women attending Sunshine Hospital, Australia, between 1st July 2012 and 30th June 2013. We fitted logistic regression models to assess the association between COB and GDM. An interaction between BMI and COB was assessed by likelihood ratio test. Results. In the 4610 included in our analysis, most common were women born in Australia or New Zealand (ANZ, 1932, 41.9\%) and in Southeast Asia (922, 20\%). GDM was diagnosed in 606 (13.2\%) women. After adjusting for confounders, women from East Asia were most likely to develop GDM (37, 24.0\%) and 5-fold more likely than women from ANZ $(\mathrm{OR}=4.77,95 \% \mathrm{CI}: 3.12,7.31, p<0.001)$. Women from other Asian countries had a 3 -fold increased risk of GDM compared to women from ANZ. There was no evidence of an interaction by BMI $(p=0.24)$. Conclusions. Women born in Asia have higher risk of GDM compared to women born in ANZ. These data provide support for including COB in GDM management policies.
\end{abstract}

\section{Introduction}

Gestational diabetes mellitus (GDM) is a condition that affects $6.5 \%$ of pregnant women in Australia [1] and is increasing in prevalence in Australia and worldwide [2,3]. It is associated with wide reaching, sometimes long term and potentially severe, effects for both the mother and her child many of which can be ameliorated by lifestyle and pharmacological treatment of GDM [4]. These include increased perinatal mortality rates, major pregnancy, labour, and postdelivery complications, and an increased risk of obesity and metabolic syndrome in the offspring $[2,5-7]$. However, there is increasing recognition that GDM may present and behave differently in women of different ethnicities and backgrounds. This makes it important to understand specific local population characteristics when designing and implementing local services. Australia's multicultural composition is frequently described as being intrinsic to Australian identity. One in four Australians were born overseas and 44\% were either born overseas or had a parent who was, and this number is increasing $[8,9]$. The proportion of Australians born in Europe has declined in recent years while there has 
been a significant increase in the populations of Australians who were born in Central, South, and Southeast Asia [9]. Western Health, in Melbourne, Victoria, Australia, services a very ethnically diverse population. In particular, the region hosts a large South Asian and Southeast Asian community who are known to be at particular risk of developing GDM [10]. Migrant women of any ethnicity are more prone to GDM in comparison to women of both their birth and host countries although reasons for this may be varied $[11,12]$.

Race/ethnicity and obesity are two of the strongest independent risk factors for GDM [13-17]. There is a positive association between an unhealthy weight and the development of GDM seen for all ethnicities but the strength of the association appears to be variable between ethnicities. The strongest association is found in women of South Asian and Black African ethnicities whereas the association seems to be weaker for other Asian groups $[15,16]$. One study reported that the association between body mass index (BMI) and GDM appeared to plateau at a BMI around $28 \mathrm{~kg} / \mathrm{m}^{2}$ in Asian groups but continued past a BMI of $35 \mathrm{~km} / \mathrm{m}^{2}$ in other groups [16]. Pregnant Asian women appear to have a greater degree of insulin resistance than Caucasian women at similar BMIs and demonstrate a stronger association between prepregnancy BMI and insulin resistance. This may partly be explained by a greater central adiposity and percentage of body fat in people of Asian descent [17].

The World Health Organisation (WHO) has recognised that a healthy weight range, based on studies of risk factors and morbidities, varies with the ethnicity of the population studied [17] and may be lower (e.g., Southeast Asian populations) or higher (e.g., Pacific Islanders) than for Caucasians [18]. Therefore, cut-offs derived from European data do not provide an adequate basis for taking action on risks related to overweight and obesity. It suggests that the increased risk of health problems associated with increasing BMI must be regarded as being on a continuum with increasing BMI [17].

Local populations must be well understood in order to develop and implement policies that will provide the greatest benefit. A previous evaluation, in 1991, of GDM prevalence in a similar Australian population has found that rates may be tripled in women of Indian subcontinental and other Asian origins compared to women from Australia and New Zealand (ANZ) [19]. Australia is increasingly multiethnic and the prevalence of GDM is known to be increasing $[2,3,19,20]$ making reevaluation pertinent. This is particularly relevant given the changing immigration patterns over time. The current study aimed to determine the prevalence of GDM in a widely multiethnic population of women who presented to Western Health for pregnancy care and assess whether the association between body mass index (BMI) and GDM prevalence is modified by ethnicity.

\section{Materials and Methods}

2.1. Ethical Approval. This study has been approved by the Western Health Low Risk ethics panel (QA Reference Number: QA2014.111) and it conforms to the provisions of the Declaration of Helsinki (as revised in Seoul, 2008).
2.2. Design and Participants. All women who gave birth at Sunshine Hospital between 1st July 2012 and 30th June 2013 were included in this retrospective cohort study. Women with diabetes mellitus types one (T1DM) or two (T2DM) were excluded. We also excluded women who presented to the hospital with an already established diagnosis of GDM in the current pregnancy. Sunshine Hospital receives referrals from smaller centres of women excluded from care at these centres following their diagnosis with GDM. Excluding these women from analysis avoided overestimation of GDM as a result of these referrals. We used BOS (Birthing Outcome System), a specialised pregnancy related clinical information system, to access demographics and pregnancy outcomes data. The outcome measure was diagnosis of GDM. The maternal BMI was recorded at the first visit. Cases with missing BMI, country of birth (COB), age, or oral glucose tolerance test (OGTT) data were excluded. Also, cases with a BMI recorded as less than 16 were excluded in order to eliminate cases in which a patient's height or weight had been omitted or incorrectly entered into the height or weight fields. Cases with a BMI greater than 50 were manually reviewed to ensure their accuracy.

Our centre used the Australian Diabetes in Pregnancy Society (ADIPS) guidelines for the testing and diagnosis of GDM initially published in 1991 [20]. In accordance with this guideline, women were diagnosed with GDM if one or both of the following criteria were met during $75 \mathrm{~g}$ glucose bolus OGTT:

(i) Fasting blood glucose level $\geq 5.5 \mathrm{mmol} / \mathrm{L}$.

(ii) 2 hours after a $75 \mathrm{~g}$ glucose bolus, blood glucose level $\geq 8.0 \mathrm{mmol} / \mathrm{L}$.

Women underwent risk based screening in early pregnancy. Remaining women and women in whom OGTT was negative on early screening underwent universal screening at 24 to 26 weeks gestation.

For each woman identified through BOS as having a diagnosis of GDM, we confirmed that the results of the OGTT were concordant with a diagnosis of GDM according to the ADIPS criteria. We then extracted further information regarding any prior OGTTs and the endocrinological management after diagnosis of GDM.

Patients were considered to have GDM regardless of the gestational age at diagnosis so long as pregestational T1DM or T2DM was excluded.

Screening and management protocols were consistent with the ADIPS guidelines and included routine testing with an OGTT for all women (without a prior glucose challenge test) at 26-28 weeks except where tested for and diagnosed earlier in pregnancy. Management involved early consultation with a credentialed diabetes educator and a dietician and self-monitoring of capillary blood glucose before and after meals. Insulin therapy was initiated if women were unable to meet ADIPS treatment targets with dietary and lifestyle modification. Adherence to these treatment guidelines was not assessed in this study.

$\mathrm{COB}$, established by self-report at first visit, was used as a proxy for ethnicity. Women were then allocated to one 
TABLE 1: List of included countries by region.

\begin{tabular}{|c|c|c|c|c|}
\hline \multirow[t]{2}{*}{ Region } & \multicolumn{4}{|c|}{ Country of birth } \\
\hline & Albania & Herzegovina & Russia & Wales \\
\hline \multirow{10}{*}{ Europe and North America } & Belgium & Hungary & Scotland & Bermuda \\
\hline & Bosnia & Ireland & Serbia & Canada \\
\hline & Bulgaria & Italy & Slovakia & United States \\
\hline & Croatia & Lithuania & Slovenia & \\
\hline & England & Malta & Spain & \\
\hline & Finland & Montenegro & Sweden & \\
\hline & $\begin{array}{c}\text { Former } \\
\text { Yugoslav } \\
\text { Republic of } \\
\text { Macedonia }\end{array}$ & Norway & Switzerland & \\
\hline & France & Poland & Ukraine & \\
\hline & Germany & Portugal & Oman & \\
\hline & Greece & Romania & United Kingdom & \\
\hline \multirow{3}{*}{ Arab States } & Bahrain & Jordan & & United Arab Emirates \\
\hline & Egypt & Kuwait & Saudi Arabia & Yemen \\
\hline & Iraq & Lebanon & Syria & \\
\hline \multirow{2}{*}{ West and Central Asia } & Afghanistan & Iran & Pakistan & Turkmenistan \\
\hline & Cyprus & Nepal & Turkey & \\
\hline \multirow{3}{*}{ South East Asia } & Cambodia & Laos & Thailand & Papua New Guinea \\
\hline & East Timour & Malaysia & Philippines & Vietnam \\
\hline & Indonesia & Myanmar & Singapore & \\
\hline \multirow{2}{*}{ East Asia } & China & Japan & Macau & \\
\hline & Hong Kong & Korea (South) & Taiwan & \\
\hline South Asia & Bangladesh & India & Sri Lanka & \\
\hline \multirow{6}{*}{ Africa } & Burundi & Ethiopia & Libya & Somalia \\
\hline & Chad & Gambia & Mauritius & Sudan \\
\hline & Comoros & Ghana & Morocco & Tanzania \\
\hline & Congo & Guinea & Nigeria & Togo \\
\hline & Djibouti & Kenya & Rwanda & Uganda \\
\hline & Eritrea & Liberia & Sierra Leone & Zimbabwe \\
\hline \multirow{3}{*}{ Latin America } & Argentina & Colombia & Mexico & Uruguay \\
\hline & Brazil & El Salvador & Panama & \\
\hline & Chile & Guatemala & Peru & \\
\hline \multirow[t]{2}{*}{ Oceania } & Cook Islands & Nauru & Samoa & Tonga \\
\hline & Fiji & Niue & Tokelau & Vanuatu \\
\hline ANZ & Australia & New Zealand & & \\
\hline
\end{tabular}

of the following 10 ethnic subgroups: Europe and North America, the Arab States, West and Central Asia, Southeast Asia, East Asia, South Asia, Africa, Latin America, Oceania, and Australia and New Zealand (ANZ). These groups are described in Table 1.
2.3. Data Analysis. Parity was grouped into nulliparous (parity $=0$ ), multiparous (parity $\geq 1$ and $<5$ ) and grandmultiparous (parity $\geq 5$ ). BMI was grouped into underweight $\left(<18.5 \mathrm{~kg} / \mathrm{m}^{2}\right)$, normal weight $\left(\geq 18.5\right.$ and $\left.<25 \mathrm{~kg} / \mathrm{m}^{2}\right)$, overweight $\left(\geq 25\right.$ and $\left.<30 \mathrm{~kg} / \mathrm{m}^{2}\right)$, obese $\left(\geq 30\right.$ and $\left.<35 \mathrm{~kg} / \mathrm{m}^{2}\right)$, 
5260 women gave birth at Sunshine Hospital from from 1st July 2012 to 30th June 2013

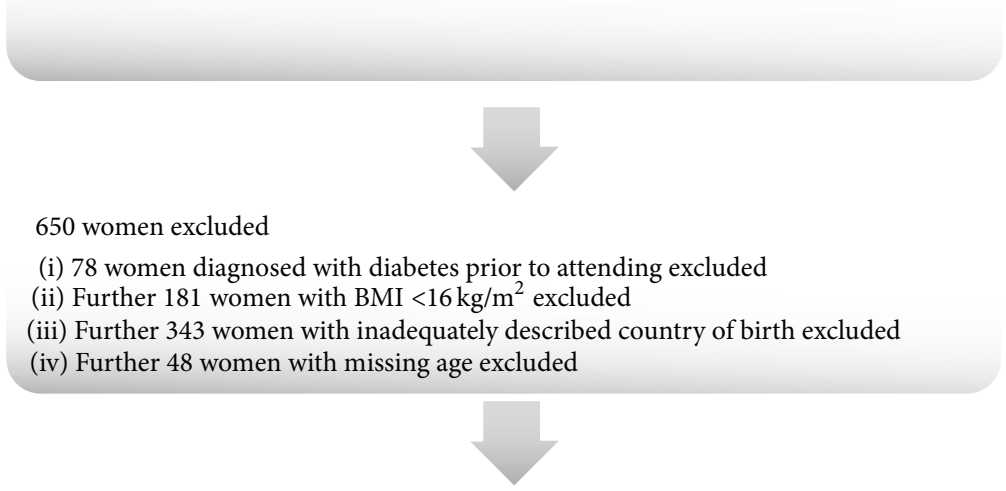

4610 women included in analysis

(i) 606 newly diagnosed with gestational diabetes

Figure 1: Flow chart of women who gave birth at Sunshine Hospital from 1st July 2012 to 30th June 2013 showing numbers included in and excluded from study.

and morbidly obese $\left(\geq 35 \mathrm{~kg} / \mathrm{m}^{2}\right)$ according to WHO groupings [14]. Maternal age was grouped in quartiles (determined by the overall maternal ages of women delivering at the hospital during this time period), with quartile 1 defined as age $\leq 26$ years, quartile 2 as age $>26$ and $\leq 29$, quartile 3 as age $>29$ and $\leq 33$, and quartile 4 as $>33$.

We fitted a univariable logistic regression model to assess the association between $\mathrm{COB}$ and presence or absence of GDM. Next, we fitted a multivariable logistic regression model to assess the above-mentioned association (i.e., the association between COB and GDM) after adjusting for age, parity, and BMI. We hypothesised $a$ priori that the association between $\mathrm{COB}$ and GDM might vary by BMI. We fitted an interaction term for $\mathrm{COB}$ and $\mathrm{BMI}$ and tested the interaction with the likelihood ratio test.

We used the likelihood ratio test to test the assumption of a (log) linear association between age and GDM. We did this by fitting a model with age grouped into quartiles and compared it to a model with age as a pseudocontinuous variable (set to the median value in each quartile). There was evidence of a nonlinear association between age and (log odds) of GDM; therefore age was included as a categorical variable.

Data were collated using Excel 2013 and were analysed using SPSS v. 20 (IBM Corp., 2011).

\section{Results}

Of the 5260 women who attended Sunshine Hospital for delivery between 1st July 2012 and 30th June 2013, 650 were excluded from our analysis. 78 women were identified as either having pregestational T1DM or T2DM or were referred to Sunshine Hospital for care after being identified as having GDM. An additional 181 women were excluded due to incomplete BMI entries. $\mathrm{COB}$ was inadequately described in a further 343 women and age was missing in a further 48 cases. Of the 4610 women included in our analyses, 606 (13.2\%) women were newly diagnosed with GDM (Figure 1).

The majority of women were born in Australia or New Zealand $(n=1932(41.9 \%))$. Other major COB groups were Southeast Asia $(n=922,20.0 \%)$ and South Asia $(n=673,14.6 \%)$. Overall, $40.9 \%$ of women were born in an Asian country $(n=1887)$. The mean age of our antenatal population was 29.2 years (Standard Deviation (SD) $=6.1$ years), median BMI was $25.0 \mathrm{~kg} / \mathrm{m}^{2}$ (Interquartile range (IQR) 22.0-29.0). Also, 1998 (43.3\%) were nulliparous and 2612 (56.7\%) were multiparous (parity $\geq 1$ ) (Table 2 ).

Table 3 presents the results from univariable and multivariable logistic regression analysis. After adjusting for age, BMI, and parity, women born in East Asia had almost 5-fold increased odds of GDM compared to women born in ANZ $(\mathrm{OR}=4.77 ; 95 \%$ confidence interval $(\mathrm{CI})=3.12,7.31$, $p$ value $<0.001)$. Similarly, women born in West and Central Asia, South Asia, and Southeast Asia had an approximately 3-fold increased risk of GDM (OR for West and Central Asia $=2.47$, 95\% CI 1.50-4.05, $p=0.01$; OR for South Asia $=3.38,95 \%$ CI 2.60-4.40, $p<0.001$; OR for South East Asia = 3.03, 95\% CI 2.34-3.93, $p<0.001$ ). There was no evidence of an interaction between $\mathrm{BMI}$ and $\mathrm{COB}$ ( $p$ from likelihood ratio test $=0.24)$.

\section{Discussion}

This study found that women born in West and Central Asia, Southeast Asia, East Asia, or South Asia had the highest 
TABLE 2: Demographic characteristics of women included in the study group.

\begin{tabular}{|c|c|}
\hline Maternal characteristics & $\begin{array}{c}\text { Number }(\%) \\
(N=4610)\end{array}$ \\
\hline \multicolumn{2}{|l|}{ Country of birth } \\
\hline Australia or New Zealand & $1932(41.9)$ \\
\hline Arab States & $111(2.4)$ \\
\hline West and Central Asia & $138(3.0)$ \\
\hline Southeast Asia & $922(20.0)$ \\
\hline East Asia & $154(3.3)$ \\
\hline South Asia & $673(14.6)$ \\
\hline Africa & $354(7.7)$ \\
\hline Latin America & $41(0.9)$ \\
\hline Oceania & $83(1.8)$ \\
\hline Europe and North America & $202(4.4)$ \\
\hline Age $(\text { years })^{\dagger}$ & $29.2 \pm 6.1$ \\
\hline 1st quartile ( $\leq 26$ years) & $1360(29.5)$ \\
\hline 2nd quartile ( $>26$ and $\leq 29$ years) & 1009 (21.9) \\
\hline 3 rd quartile ( $>29$ and $\leq 33$ years) & $1186(25.7)$ \\
\hline 4th quartile ( $>33$ years) & $1055(22.9)$ \\
\hline \multicolumn{2}{|l|}{ Parity } \\
\hline Nulliparous (parity $=0$ ) & $1998(43.3)$ \\
\hline Multiparous (parity 1 to 4 ) & $2484(53.9)$ \\
\hline Grand multiparity (parity $\geq 5$ ) & $128(2.8)$ \\
\hline \multicolumn{2}{|l|}{ Body mass index $\left(\mathrm{kg} / \mathrm{m}^{2}\right)$} \\
\hline Underweight $(<18.5)$ & $198(4.3)$ \\
\hline Normal $(\geq 18.5$ and $<25)$ & $2066(44.8)$ \\
\hline Overweight $(\geq 25$ and $<30)$ & $1231(26.7)$ \\
\hline Obese $(\geq 30$ and $<35)$ & $556(12.1)$ \\
\hline Morbidly obese $(\geq 35)$ & $559(12.1)$ \\
\hline
\end{tabular}

${ }^{\dagger}$ Mean and standard deviation.

risks of GDM compared to women born in Australia or New Zealand. Ethnicity and BMI are recognised to have the strongest association with GDM.

Hedderson et al. (2012) [16] reported that increasing BMI is associated with an increased prevalence of GDM for all ethnic groups but that this effect was stronger for White, Hispanic, and African American women than for Asian women, whereas Kim et al. (2013) found the strongest association between Indian and Black African women and the weakest between other Asian groups [15]. However, Kim et al. also found substantial subgroup variability in the Asian cohort [15]. An interaction between $\mathrm{COB}$ and BMI in the association with GDM was not found in our data. In our study, there were very few Asian women who were obese and morbidly obese. This may have limited our ability to completely explore such an interaction. In practice though, the low prevalence of obese and morbidly obese Asian women must limit the utility of using traditional BMI cut-offs to predict GDM in Asian women. However, the findings of the present study do not support the use of racially specific BMI cut-offs in screening protocols. This is in line with the most recent $\mathrm{WHO}$ guidance. The WHO has recognised that BMI cut-offs for observed health risks are very specific to relatively small ethnic groups [17] and therefore suggests treating BMI associated risk as a continuum.

The reasons why migrant Asian women have a higher risk of GDM are diverse and unclear. Asian persons are at greater risk of T2DM, the aetiology of which may partially explain their predisposition for GDM [21]. Asian women display greater insulin resistance in pregnancy after age, weight gain in pregnancy, and history of diabetes are removed, and the association between prepregnancy BMI and insulin resistance is greater [22]. Renzaho et al. (2010) [12] cite a disruption of normal eating habits, dietary acculturation, lack of physical activity, and rapid weight gain after dietary restriction as possible lifestyle mediators. Bandyopadhyay et al. (2011) [3] reported that South Asian migrant women with culturally different food and exercise habits reported difficulty initiating and sustaining appropriate diet and exercise regimens.

The present study was limited by being retrospective. It is recognised that country of birth may not always reflect ethnicity. In particular, the population of women born in Australia or New Zealand may already be ethnically diverse. This may have increased the heterogeneity of our groups. We were unable to control for other factors commonly associated with the development of GDM such as diet and exercise. It has been previously suggested that diet and exercise may explain part of the association between COB and GDM (discussed above). Also, we sampled very small numbers of obese and morbidly obese women, despite a large sample size. This may have limited our ability to completely explore an interaction between $\mathrm{BMI}$ and $\mathrm{COB}$ as discussed above.

Regardless of the reasons for which ethnicity affects risk of diabetes, this study, performed in a multiethnic population, supports the need for ethnicity to be included in GDM screening as well as in management guidelines and policies. There is a need for widespread early screening in at-risk ethnic groups and for early implementation of culturally sensitive management techniques that may ameliorate the barriers identified by Bandyopadhyay et al. (2011) [3]. Future studies may investigate ethnic differences in the development of early onset GDM when all women are tested prior to 20 weeks gestation and investigate the utility of early interventions.

\section{Conflict of Interests}

The authors have no conflict of interests to disclose including specific financial interests or relationships or affiliations other than those previously mentioned relevant to the subject of this paper. 
TABLE 3: Results of univariable and multivariable logistic regression for presence or absence of gestational diabetes mellitus (GDM) in 4610 women at Sunshine Hospital, Australia.

\begin{tabular}{|c|c|c|c|c|c|c|}
\hline \multirow{2}{*}{ Characteristics } & \multicolumn{2}{|c|}{ GDM } & \multicolumn{2}{|c|}{ Univariable analysis } & \multicolumn{2}{|c|}{ Multivariable $^{\dagger}$ analysis } \\
\hline & GDM $(n)$ & No GDM $(n)$ & Odds ratio $(95 \% \mathrm{CI})$ & $p$ value & Odds ratio (95\% CI) & $p$ value \\
\hline \multicolumn{7}{|l|}{ Country of birth } \\
\hline Australia or New Zealand & 175 & 1757 & 1.00 & & 1.00 & \\
\hline Arab States & 12 & 99 & $1.21(0.65,2.24)$ & 0.55 & $1.33(0.71,2.50)$ & 0.37 \\
\hline West and Central Asia & 22 & 116 & $1.89(1.17,3.06)$ & 0.01 & $2.47(1.50,4.05)$ & $<0.001$ \\
\hline Southeast Asia & 161 & 761 & $2.11(1.68,2.66)$ & $<0.001$ & $3.03(2.34,3.93)$ & $<0.001$ \\
\hline East Asia & 37 & 117 & $3.16(2.11,4.71)$ & $<0.001$ & $4.77(3.12,7.31)$ & $<0.001$ \\
\hline South Asia & 136 & 537 & $2.59(2.03,3.30)$ & $<0.001$ & $3.38(2.60,4.40)$ & $<0.001$ \\
\hline Africa & 34 & 320 & $1.12(0.77,1.63)$ & 0.56 & $1.24(0.83,1.84)$ & 0.29 \\
\hline Latin America & 4 & 37 & $0.73(0.42,1.29)$ & 0.28 & $0.90(0.51,1.60)$ & 0.72 \\
\hline Oceania & 11 & 72 & $1.06(0.37,3.00)$ & 0.91 & $0.94(0.33,2.70)$ & 0.91 \\
\hline Europe and North America & 14 & 188 & $1.52(0.79,2.91)$ & 0.21 & $1.12(0.57,2.19)$ & 0.74 \\
\hline \multicolumn{7}{|l|}{ Age (per year) } \\
\hline 25 th centile (<26 years) & 144 & 1216 & 1.00 & & 1.00 & \\
\hline 50th centile ( $\geq 26$ and $<29$ years) & 121 & 888 & $1.15(0.89,1.49)$ & 0.28 & $1.02(0.78,1.33)$ & 0.88 \\
\hline 75 th centile ( $\geq 29$ and $<33$ years) & 146 & 1040 & $1.19(0.93,1.51)$ & 0.17 & $1.05(0.82,1.35)$ & 0.71 \\
\hline$\geq 75$ th centile ( $\geq 33$ years) & 195 & 860 & $1.91(1.52,2.42)$ & $<0.001$ & $1.70(1.34,2.17)$ & $<0.001$ \\
\hline \multicolumn{7}{|l|}{ Body mass index $\left(\mathrm{kg} / \mathrm{m}^{2}\right)$} \\
\hline Underweight $(<18.5)$ & 22 & 176 & $0.92(0.64,1.32)$ & 0.64 & $0.96(0.60,1.54)$ & 0.87 \\
\hline Normal $(\geq 18.5$ and $<25)$ & 221 & 1845 & 1.00 & & 1.00 & \\
\hline Overweight $(\geq 25$ and $<30)$ & 184 & 1047 & $1.47(1.20,1.81)$ & $<0.001$ & $1.72(1.38,2.14)$ & $<0.001$ \\
\hline Obese $(\geq 30$ and $<35)$ & 84 & 472 & $1.50(1.15,1.95)$ & 0.003 & $2.14(1.60,2.86)$ & $<0.001$ \\
\hline Morbidly obese ( $\geq 35)$ & 95 & 464 & $1.70(1.32,2.20)$ & $<0.001$ & $3.16(2.34,4.27)$ & $<0.001$ \\
\hline \multicolumn{7}{|l|}{ Parity } \\
\hline Nulliparous (parity = 0) & 259 & 1739 & 1.00 & & 1.00 & \\
\hline Multiparous (parity 1 to 4 ) & 321 & 2163 & $1.01(0.85,1.19)$ & 0.96 & $1.00(0.83,1.19)$ & 0.98 \\
\hline Grand multiparity (parity $\geq 5$ ) & 26 & 102 & $1.73(1.12,2.66)$ & 0.01 & $1.80(1.13,2.86)$ & 0.01 \\
\hline Total & 606 & 4004 & & & & \\
\hline
\end{tabular}

${ }^{\dagger}$ The multivariable analyses are adjusted for the other remaining maternal characteristics listed in the table. Nagelkerke $R^{2}=0.08$. 95\% CI: 95\% confidence interval.

\section{Acknowledgments}

The authors thank staff in the Women's and Children's Service, Sunshine Hospital, and, in particular, Linda Campbell, Birthing Outcome System Manager, for her help with data collection.

\section{References}

[1] Z. Li, R. Zeki, L. Hilder, and A. Sullivan, Eds., Australia's Mothers and Babies: 2011, Perinatal Statistics Series No. 28. Cat. No. PER 59, AIHW National Perinatal Epidemiology and Statistics Unit, Canberra, Canada, 2011.

[2] T. Sathyapalan, D. Mellor, and S. L. Atkin, "Obesity and gestational diabetes," Seminars in Fetal \& Neonatal Medicine, vol. 15, no. 2, pp. 89-93, 2010.

[3] M. Bandyopadhyay, R. Small, M.-A. Davey, J. J. N. Oats, D. A. Forster, and A. Aylward, "Lived experience of gestational diabetes mellitus among immigrant South Asian women in Australia," Australian and New Zealand Journal of Obstetrics and Gynaecology, vol. 51, no. 4, pp. 360-364, 2011.
[4] C. A. Crowther, J. E. Hiller, J. R. Moss, A. J. McPhee, W. S. Jeffries, and J. S. Robinson, "Effect of treatment of gestational diabetes mellitus on pregnancy outcomes," The New England Journal of Medicine, vol. 352, no. 24, pp. 2477-2486, 2005.

[5] H. E. Mighty and J. O. Fahey, "Obesity and pregnancy complications," Current Diabetes Reports, vol. 7, no. 4, pp. 289-294, 2007.

[6] A. W. Shand, J. C. Bell, A. McElduff, J. Morris, and C. L. Roberts, "Outcomes of pregnancies in women with pre-gestational diabetes mellitus and gestational diabetes mellitus; a populationbased study in New South Wales, Australia, 1998-2002," Diabetic Medicine, vol. 25, no. 6, pp. 708-715, 2008.

[7] The HAPO Study Cooperative Research Group, "Hyperglycemia and adverse pregnancy outcomes," The New England Journal of Medicine, vol. 358, no. 19, pp. 1991-2002, 2008.

[8] C. Bowen and K. Lundy, Eds., The People of Australia: Australia's Multicultural Policy, The Australian Multicultural Advisory Council, Canberra, Australia, 2014.

[9] Australian Bureau of Statistics, "Migration, Australia, 2011-12 and 2012-13," Cat. no. 3412.0., 2015, http://www.abs.gov.au/ AUSSTATS/abs@.nsf/DetailsPage/3412.02011-12\%20and\%202012 -13 ? 
[10] H. G. Dahlen, V. Schmied, C.-L. Dennis, and C. Thornton, "Rates of obstetric intervention during birth and selected maternal and perinatal outcomes for low risk women born in Australia compared to those born overseas," BMC Pregnancy and Childbirth, vol. 13, article 100, 2013.

[11] M. Abouzeid, V. L. Versace, E. D. Janus et al., "A populationbased observational study of diabetes during pregnancy in Victoria, Australia, 1999-2008," BMJ Open, vol. 4, Article ID e005394, 2014.

[12] A. M. N. Renzaho, H. Skouteris, and J. Oldroyd, "Preventing gestational diabetes mellitus among migrant women and reducing obesity and type 2 diabetes in their offspring: a call for culturally competent lifestyle interventions in pregnancy," Journal of the American Dietetic Association, vol. 110, no. 12, pp. 1814-1817, 2010.

[13] HAPO Study Cooperative Research Group, "Hyperglycaemia and adverse pregnancy outcome (HAPO) study: associations with maternal body mass index," BJOG, vol. 117, no. 5, pp. 575$584,2010$.

[14] A. Shah, N. E. Stotland, Y. W. Cheng, G. A. Ramos, and A. B. Caughey, "The association between body mass index and gestational diabetes mellitus varies by race/ethnicity," American Journal of Perinatology, vol. 28, no. 7, pp. 515-520, 2011.

[15] S. Y. Kim, C. Saraiva, M. Curtis et al., "Fraction of gestational diabetes mellitus attributable to overweight and obesity by race/ ethnicity, California, 2007-2009," American Journal of Public Health, vol. 103, no. 10, pp. e65-e72, 2013.

[16] M. Hedderson, S. Ehrlich, S. Sridhar, J. Darbinian, S. Moore, and A. Ferrara, "Racial/ethnic disparities in the prevalence of gestational diabetes mellitus by BMI," Diabetes Care, vol. 35, no. 7, pp. 1492-1498, 2012.

[17] World Health Organisation Expert Consultation, "Appropriate body-mass index for Asian populations and its implications for policy and intervention strategies," The Lancet, vol. 363, no. 9403, pp. 157-163, 2004.

[18] S. Inoue and P. Zimmet, Redefining Obesity and Its Treatment, World Health Organization Western Pacific Region, International Association for the Study of Obesity, International Obesity Task Force, 2000.

[19] N. A. Beischer, J. N. Oats, O. A. Henry, M. T. Sheedy, and J. E. Walstab, "Incidence and severity of gestational diabetes mellitus according to country of birth in women living in Australia," Diabetes, vol. 40, supplement 2, pp. 35-38, 1991.

[20] F. I. R. Martin, "The diagnosis of gestational diabetes. Ad Hoc Working Party," Medical Journal of Australia, vol. 155, no. 2, p. 112, 1991.

[21] A. Ramachandran, R. C. Wan Ma, and C. Snehalatha, "Diabetes in Asia," The Lancet, vol. 375, no. 9712, pp. 408-418, 2010.

[22] R. Retnakaran, A. J. G. Hanley, P. W. Connelly, M. Sermer, and B. Zinman, "Ethnicity modifies the effect of obesity on insulin resistance in pregnancy: a comparison of Asian, South Asian, and Caucasian women," Journal of Clinical Endocrinology and Metabolism, vol. 91, no. 1, pp. 93-97, 2006. 


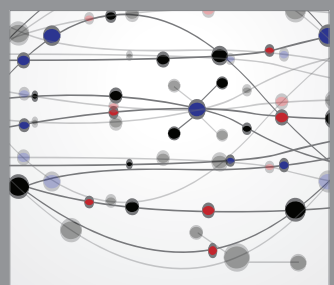

The Scientific World Journal
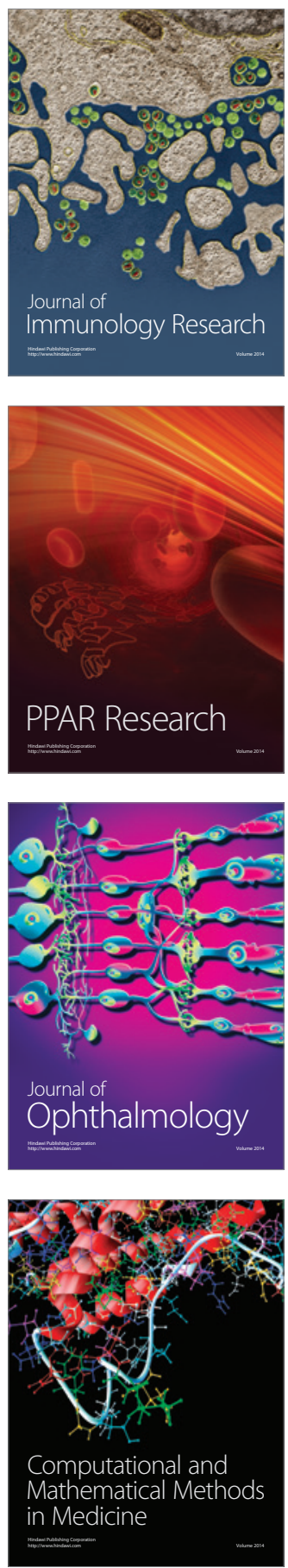

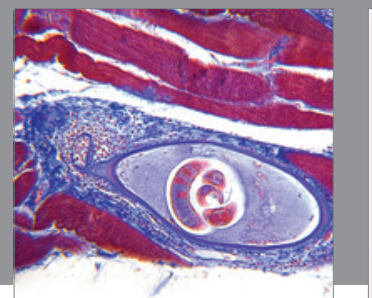

Gastroenterology

Research and Practice
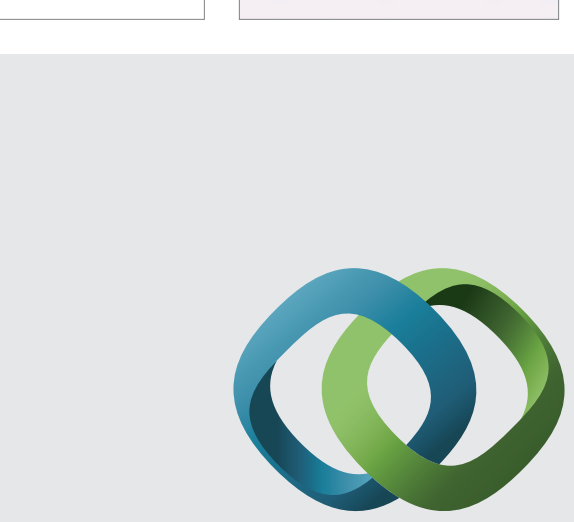

\section{Hindawi}

Submit your manuscripts at

http://www.hindawi.com
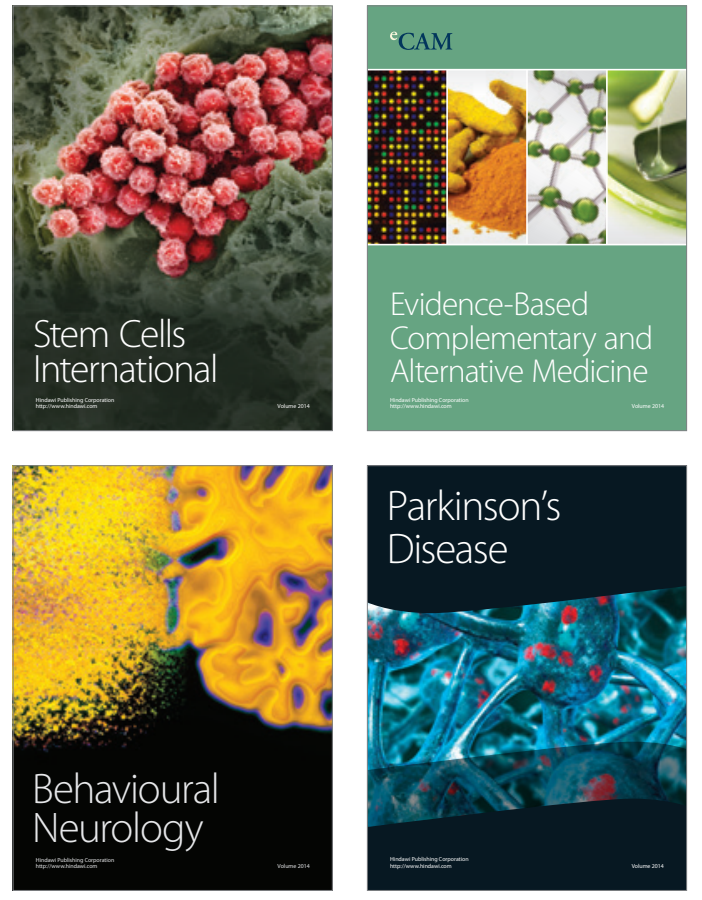
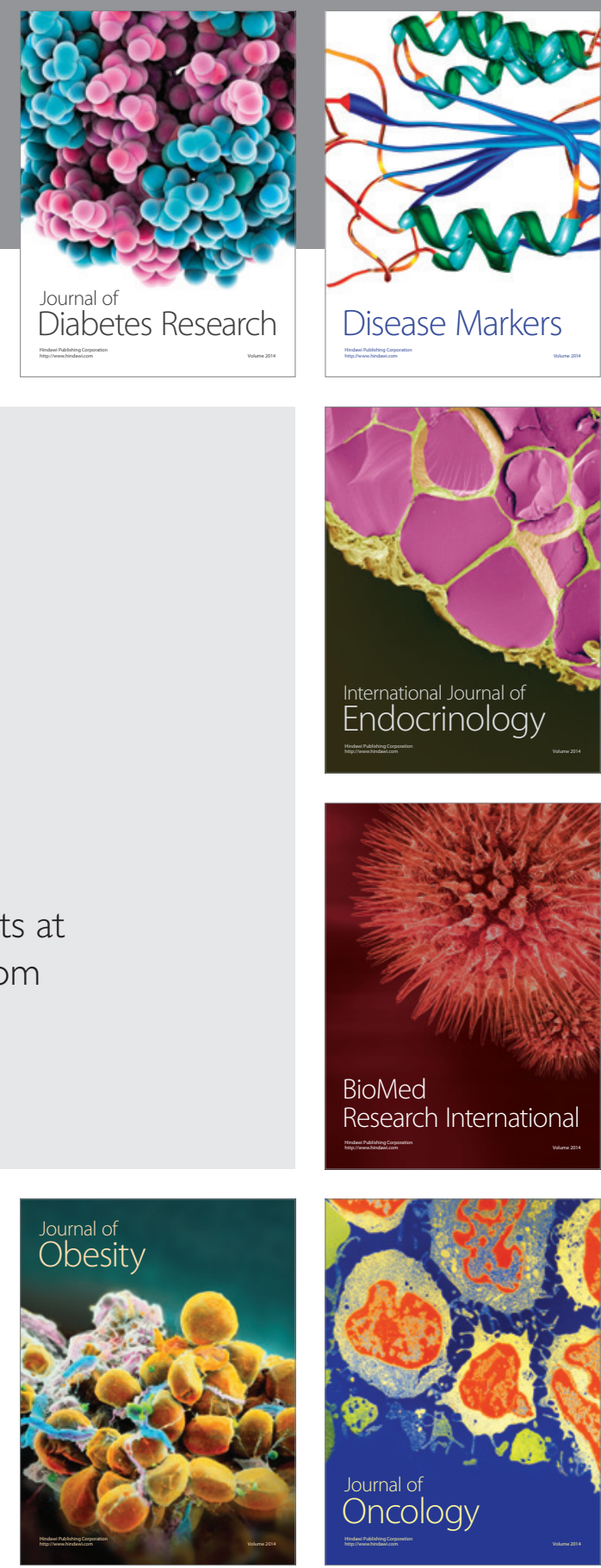

Disease Markers
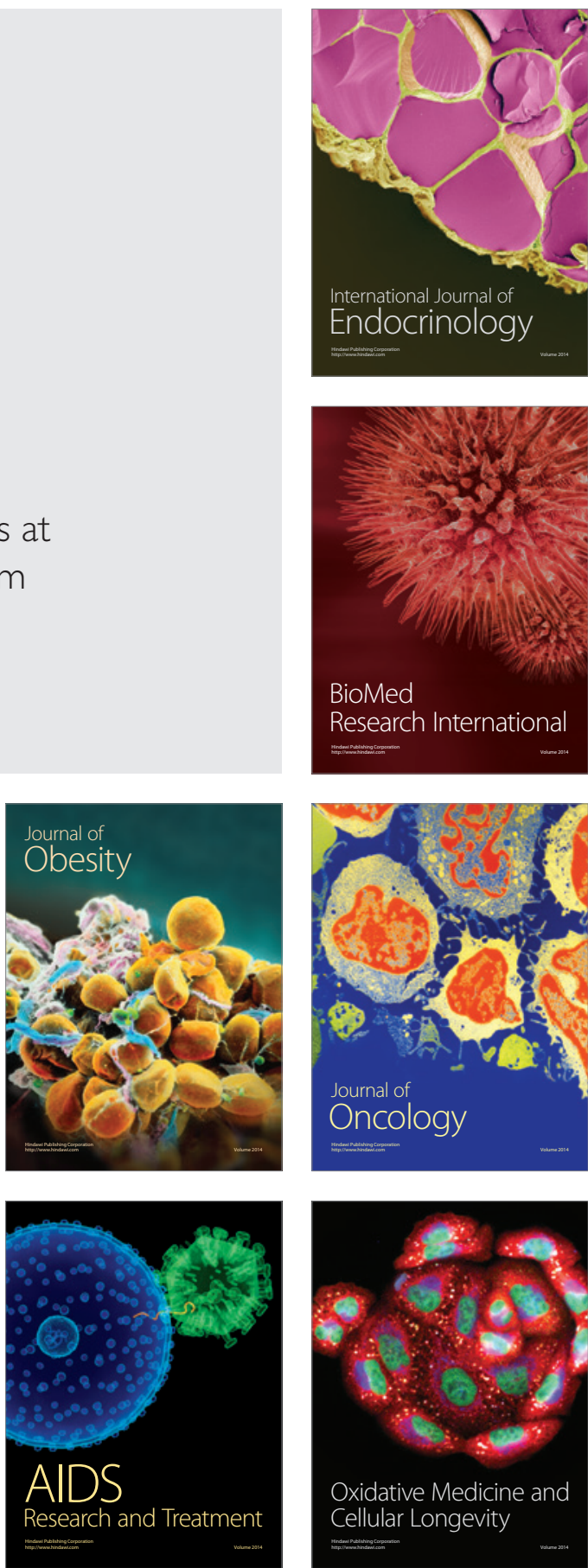